be in accordance with the laws of physics. As regards dictum (2): If a small volume of gas be introduced into the pleural cavity and the needle be immediately withdrawn, the gas will be subject to the following forces, $(a)$ capillary attraction between the layers of the pleura, tending to keep it in position, and $(b)$ during respiration to alternate increase and diminution of pressure. It is a justifiable assumption that the increase of pressure during expiration is greater than the pleural capillarity, consequently the gas will be driven to any part of the pleural cavity, where it will be least subject to compression, and, as Dr. Parry Morgan has shown, will take up a position opposite any consolidated portion of lung. But if the needle connected with the manometer has not been withdrawn the conditions are altered. Capillary attraction still exerts its limiting action, but alterations in pressure are met by the movement of a corresponding portion of gas to or from the manometer. Therefore, the gas does not move away from the needle, as its position is already one in which increase in pressure cannot affect it. It will be accommodated by a conical delling of the lung, the base of the cone being roughly circular with its centre at the point of the needle (a mathematical person might calculate the area of this circle for any volume of gas), and this, provided the needle has not been pushed in to an unjustifiable extent, disposes of dictum number (3). Therefore, provided the lung has not been punctured, the manometer will accurately register intrapleural pressures, and respiration will be accompanied by corresponding free oscillations. I am, Sir, yours faithfully,

Rayleigh, August 23rd, 1914.

W. Mither.

\section{ANTITYPHOID INOCULATION IN WAR TIME.}

To the Editor of THE LANCET.

SIR,-On behalf of the Research Defence Society, which represents the general opinion of all who have studied the facts of antityphoid inoculation we desire to say that the society very strongly approves of this treatment for all men and women who are likely in the near future to come in contact with typhoid fever. We have accordingly offered the services of this society to the Royal Army Medical Corps.

We are, Sir, yours faithfully,

LAMINGTON, President.

F. M. SANDWrTH, M.D.Durh., F.R.C.P.Lond., Honorary Treasurer.

Stephen Paget, F.R.C.S.Eng., Honorary Secretary.

21, Ladbroke-square, W., Sept. 11th, 1914.

\section{EMETINE IN THE TREATMENT OF CHOLERA.}

To the Edutor of THE LANCET.

SIR,-I have just read in your issue of Sept. 12th an annotation dealing with the successful treatment of Asiatic cholera by emetine. This reminds me of an experience of my own during the epidemic in the island of Ischia, near Naples, when I was resident physician to the late Lord Holland.

Cholera was decimating the population of the island when we arrived there in June, 1854. Having had a three months' apprenticeship while discharging the duties of house physician at King's
College Hospital in the autumn of 1849 I was able to test and to appreciate the value of emetics administered in the earlier stages of the disease. Not having many drags at hand in the island I fell back upon hot salt and water, and found that if by half-pint doses of this mixture I could ensure copious vomiting for three or four hours the malady might be checked and life preserved.

Reference to your journal during the autumn of 1849 would, I believe, show that this treatment was originally suggested by Dr. Beaman, a general practitioner then living, I think, not far from Covent Garden. I am, Sir, yours faithfully,

Worthing, Sept. 14th, 1914.

I. D. ChepmelL.

** Mr. George Beaman, of King-street, Corent Garden, W.C., described in THE LANCET of August 23rd, 1834, the successful treatment of 11 successive cases of cholera by saline emetics, disclaiming " merit for originality of system." In THE LANCET of Angust 11th, 1849, there will be found a synopsis of the treatment adopted by ten of the metropolitan general hospitals during an epidemic of cholera. "Mr. Beaman's treatment" is referred to as being employed at King's College Hospital. We thank our old Paris Correspondent for his interesting note.-ED. L.

\section{CALCIUM CONTENT OF BLOOD IN SYPHILIS.}

To the Editor of THE LANCET.

Sir,-Professor F. W. Andrewes recently suggested to me that it would be useful to estimate the calcium content of the blood in patients suffering from primary, secondary, and tertiary syphilis. The following results show fairly well certain apparent differences between the normal individual and the syphilitics. My reason for publishing them is to learn if others who may have done similar work have had like results. Wright's method with throttled glass tube and a solution of ammonium oxalate of known strength was used; all dilutions were made with normal saline solution. The determining factor was the strongest solution of ammonium oxalate in which a clot appeared.

Normal man ... ... with 1 in 140 s sol. = clot.

\begin{tabular}{|c|c|c|c|c|c|c|c|c|}
\hline Primary sy & an $\ldots$ & ", & & , & $\begin{array}{l}1400 \\
1400\end{array}$ & ", & $\begin{array}{l}= \\
=\end{array}$ & ", \\
\hline " & ", & , & & , & 1400 & , & $=$ & , \\
\hline " & ", & " & & , & 1200 & $"$ & $=$ & \\
\hline " & ", & ,, & & , & 1200 & ," & $=$ &, \\
\hline " & " & " & & , & 1200 & ", & $=$ & \\
\hline ", & ," & ,, & &, & 1200 & ", & $=$ & 21 \\
\hline & ", & ", & & , & 1200 & , & $=$ & \\
\hline Secondary & $"$ & ,. & & , & 800 & , & $=$ & \\
\hline ". & ," & ", & . & , & 1000 & " & $=$ & ", \\
\hline ," & ", & " & 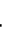 & , & 1200 & ,, & $=$ & \\
\hline ", & ", & ", & L & ", & 1000 & ", & $=$ & ", \\
\hline ", & ., & ," & [ & " & 1200 & ,, & $=$ & ", \\
\hline " & ", & ,. & 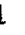 & , & 1000 & ," & $=$ & "q \\
\hline ", & ," & ", & 1 & , & 1200 & ," & $=$ & ," \\
\hline ," & ", & ", & $L$ & , & 1000 & ,, & $=$ & \\
\hline " & ," & ," & L & , & 1000 & ," & $=$ & ," \\
\hline "s & $"$ & ", & L & , & 1000 & , & $=$ & , \\
\hline "я & ," & " & 1 & , & 1000 & , & $=$ & , \\
\hline " & ," & " & 1 & , & 800 & , & $=$ & +9 \\
\hline " & " & . & 1 & ," & 1000 & ", & $=$ & " \\
\hline$"$ & $"$ & ", & 1 & ," & 1000 & , & $=$ & ," \\
\hline ", & ", & ," & 1 & ," & 1000 & ," & $=$ & ," \\
\hline ertiary & ", & ," & 1 & ", & 1200 & ", & $=$ & " \\
\hline$"$ & ", & $"$ & 1 & , & 1200 & , & $=$ & \\
\hline ", & ", & ", & I & , & 1200 & ," & $=$ & ", \\
\hline " & ," & ," & 1 & ," & 1200 & ", & $=$ & \\
\hline
\end{tabular}

(Untreated).

(Some treatment) (Untreated).

(Some treatment). (606).

(Untreated).

(Untreated).

(606 and injection). (Some treatment). (606 and injection). (606 and injection). (606).

\section{(Untreated),}

(Untreated).

(606 and injection)

(606).

(Untreated)

(6C6 and injection). (606 and injection).
In a series of investigations with healthy and non-syphilitic persons I found the calcium content by Wright's method to be equivalent to a 1 in 1300 solution of ammonium oxalate. With the present 